\title{
Fim do livro?
}

\section{ARLINDO MACHADO}

$\mathrm{N}$ prefácio à obra clássica de Henry-Jean Martin (1992:14) sobre a história do livro, o historiador Lucien Febvre vislumbra metade do século XX, náo temos certeza de que [o livro] possa ainda por muito tempo continuar a desempenhar seu papel, ameaçado como está por tantas invenções baseadas em princípios totalmente diferentes". $\mathrm{Pa}$ ra o ilustre historiador, o livro, "que começou sua carreira na metade do século XV" (p.14), parece hoje resumir-se a um acontecimento datado: depois de ter contribuído para a revoluçáo do mundo moderno, ele encontra-se agora constrangido a justificar o seu papel numa sociedade governada pela velocidade, numa sociedade em que as informaçóes circulam segundo a temporalidade própria das ondas eletromagnéticas e das redes de fibras ópticas.

O modo de produçáo do livro é lento demais para um mundo que sofre mutaçóes vertiginosas a cada minuto. Os atrativos do livro empalidecem diante do turbilhăo de possibilidades aberto pelos meios audiovisuais, enquanto sua estrutura e funcionalidade padecem de uma rigidez cadavérica quando comparadas com os recursos informatizados, interativos e multimidiáticos das escrituras eletrônicas. Como se tudo não bastasse, os custos de produçáo do livro impresso crescem agora em progressão geométrica (e não apenas no Brasil), chegando mesmo a ultrapassar os custos de muitos dos novos meios, mesmo dos mais sofisticados. Ora, como se sabe, a ampla difusão a preços baixos foi a principal responsável pelo sucesso da imprensa como forma de circulaçáo de idéias a partir do Renascimento. Caso se intensifique a tendência de encarecimento progressivo e de eficácia regressiva, é de se supor que, dentro de mais algum tempo, o livro de papel será um artigo de luxo, vendido em antiquários e lojas de porcelanas para uma seleta clientela de resistentes nostálgicos.

Certamente, náo é a primeira vez que se prognostica o fim do livro. Em 1929, impressionado com a escritura icônica e vertical que tomava conta das ruas através dos anúncios luminosos, Walter Benjamin (1978:77-79) já profetizava que "o livro, na sua forma tradicional, encaminha-se para o seu fim" e que "Os enxames de gafanhotos escriturais, que hoje já obscurecem o sol do pretenso espírito dos cidadáos das 
grandes cidades, tornar-se-ão ainda mais densos nos próximos anos". No mesmo contexto, o grande pensador da modernidade chega a denunciar a obsolescência do livro no mundo contemporâneo, convertido que foi em palco de exercícios retóricos e suporte da rotina acadêmica. "Hoje, como o atual modo de produção científica o demonstra, o livro se tornou uma mediaçáo inútil entre dois diferentes sistemas de gerenciamento de informaçóes. Pois aquilo que realmente importa pode ser encontrado no fichário do pesquisador, onde ele anota suas descobertas, e o aluno que o estuda não faz outra coisa que assimilar as idéias daquele ao seu próprio fichário". Enquanto os intelectuais de seu tempo ainda discutiam a legitimidade do uso da máquina de escrever como substituta da escrita manual, Benjamin já apontava para o horizonte dos bancos de dados interativos e dos sistemas informatizados de hipertextos e hipermídias, que tendem a se impor como as formas escriturais da próxima etapa sucessora do livro impresso: "Podemos supor que novos sistemas, com formas de escritura mais versáteis, se farão cada vez mais necessários. Eles substituirão a maleabilidade da máo pela nervosidade própria dos dedos que operam comandos".

Os prognósticos de Benjamin se confirmam. Um número crescente de revistas especializadas não sáo mais editadas em papel, mas encontram-se agora disponíveis on line para assinantes dotados de um modem, uma linha telefônica e acesso a redes internacionais tipo Internet. Muitos clássicos da literatura e ensaios científicos já estáo hoje disponíveis em disquetes e podem ser lidos diretamente na tela de monitores, havendo ainda, em muitos casos, recursos para grifar trechos, marcar páginas e fazer anotaçóes à margem, bem como para imprimir trechos selecionados. A mais nova geração de editores de textos já não pode mais ser encarada como uma mera ferramenta para auxiliar a escrita, mas como uma mídia nova, completa em si mesma, uma vez que permite acrescentar aos textos um certo número de elementos audiovisuais (voz oralizada, música, imagens em movimento) que não podem mais ser impressos em papel.

Discos laser (CD-ROMs) já sáo atualmente veículos poderosos de informaçăo, não apenas pelo impressionante volume de textos que se pode neles armazenar, mas também por seus recursos inovadores, tais como a possibilidade de localizar rapidamente qualquer palavra ou conceito, de produzir elos de ligação entre diferentes partes dos textos, de modo a permitir uma leitura não linear, ou de recorrer também a fontes não verbais, tais como sons e imagens fixas ou $\mathrm{em}$ movimento. Só a título de exemplo: um dos títulos lançados no mercado internacional Great Literature Personal Library (1992) - consiste, na verdade, em uma biblioteca inteira, condensada em um único disco CD-ROM e reu- 
nindo quase 2.000 obras dentre as mais importantes do pensamento ocidental, onde se incluem os textos completos da Iliada e da Odisseia, os romances, livros de poesia e pecas de teatro que se impuseram como seminais na história da literatura (algumas obras literárias são declamadas oralmente), as obras filosóficas, científicas e religiosas que alteraram o rumo da história, e tudo isso pode ser localizado rapidamente por palavras-chave, frases, assunto, temas recorrentes, autor, época, correntes literárias ou títulos. Nos EUA, esse disco é vendido por cerca de US\$ 50,00 , valor com o qual se pode comprar no máximo três livros tradicionais impressos em papel.

\section{A memória das civilizações}

Mas talvez essa não seja a maneira mais adequada de colocar o problema. Estamos restringindo o conceito de lipro apenas à sua expressáo tipográfica, tal como se cristalizou a partir do século XV com o modelo da imprensa de Gutenberg. Tanto a argumentaçáo negativa de Febvre, quanto a positiva de Benjamin reforçam um
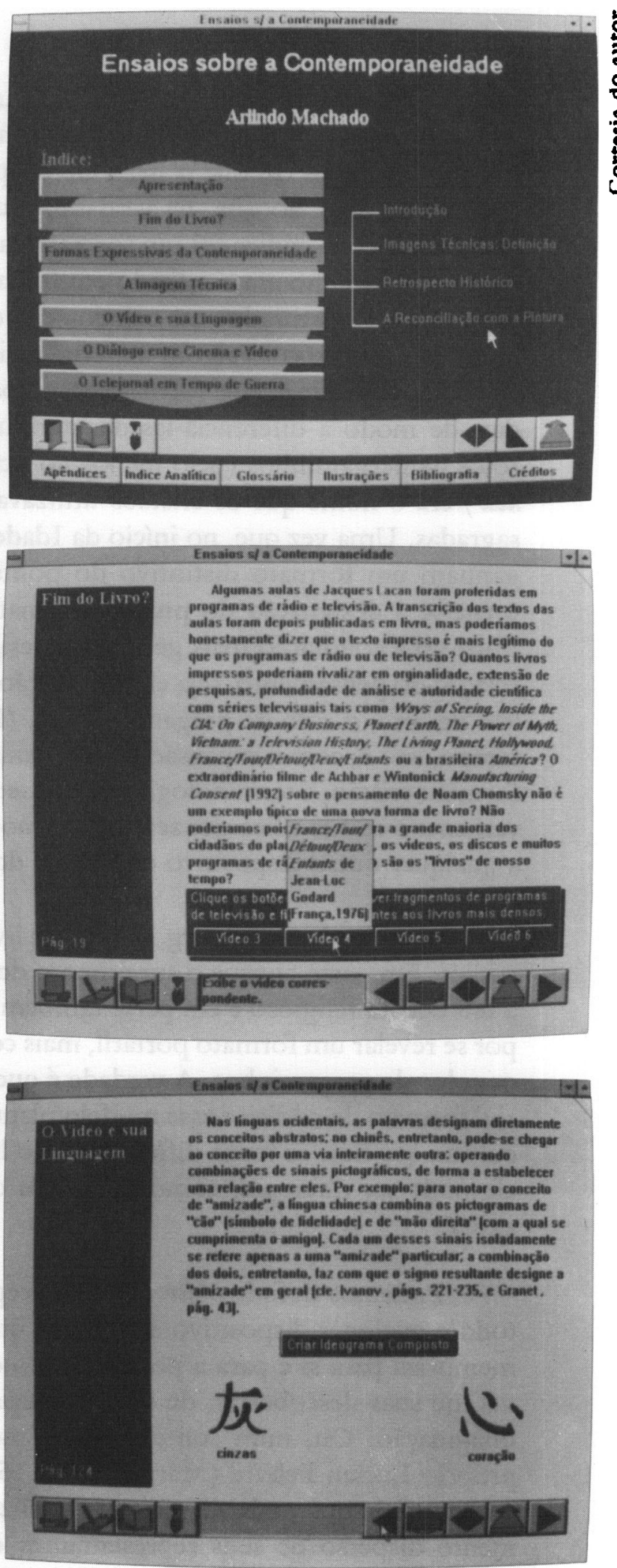

Páginas de lipro editado em CR-ROM 
pouco essa idéia de que livro é necessariamente livro impresso e sobretudo impresso em papel. Talvez esse conceito de livro esteja fadado a desaparecer, mais do que o livro ele próprio. Nós nos acostumamos a chamar de livro ao que, na verdade, é uma derivaçáo do modelo do códice cristáo. $O$ códice foi um formato característico de manuscrito em que o pergaminho era retalhado em folhas soltas, reunidas por sua vez em cadernos costurados ou colados em um dos lados e muito comumente encapados com algum material mais duro. A partir do século IV, os cristãos elegeram esse formato como padráo para as escrituras sagradas, de modo a diferenciá-las da literatura pagá, em geral escrita em rolos de pergaminhos (pelo menos no ocidente). Até então, códice (co. dex) era o nome que os cristãos utilizavam para designar as escrituras sagradas. Uma vez que, no início da Idade Média, as escrituras sagradas ganham um formato distintivo do ponto de vista material, o códice torna-se a designaçáo do próprio formato. Lipro (liber), entretanto, tinha uma conotaçáo mais genérica e designava qualquer dispositivo de fixação do pensamento, seja ele a inscrição em pedra ou madeira, a tabuleta de cera, o rolo de pergaminho etc. (Evaristo Arns, 1993). Com o tempo, isto é, com a expansáo do cristianismo e com a generalizaçáo do formato cristáo, a terminologia inverte-se: lipro passa a designar exclusivamente $o$ códice e ficamos sem um termo mais genérico para nos referir a qualquer outro dispositivo de fixaçáo do pensamento.

A Bíblia de Gutenberg, sendo um livro cristão, segue o modelo do códice. Em parte porque o surgimento do livro impresso está associado a um debate religioso e em parte também porque o livro cristáo acabou por se revelar um formato portátil, mais compacto e mais prático do que os rolos de pergaminhos. A verdade é que o livro impresso adotou para si o formato do códice e esse modelo plantou raízes tão fundas em nossa cultura que hoje se torna difícil pensar o livro como algo diferente. Mas ele pode ser diferente, como já foi em outros tempos e volta a sê-lo agora.

Podemos definir o lipro numa acepção mais ampla, como sendo todo e qualquer dispositivo através do qual uma civilizaçăo grava, fixa, memoriza para si e para a posteridade o conjunto de seus conhecimentos, de suas descobertas, de seus sistemas de crenças e os vôos de sua imaginação. $\mathrm{Ou}$, num contexto mais moderno, segundo palavras do próprio Lucien Febvre (Martin, 1992:15): livro é o instrumento mais poderoso de que pode dispor uma civilizaçáo para concentrar o pensamento disperso de seus representantes e conferir-lhe toda a eficácia, difundindo-o rapidamente no tecido social, com um mínimo de custos e de dificuldades. Sua funçáo primordial é "conferir [ao pensamento] 
um vigor centuplicado, uma coerência completamente nova $e$, por isso mesmo, um poder incomparável de penetração e de irradiaçãon.

Convenhamos que se pode atingir tais objetivos com outros meios que não necessariamente o códice cristão. No oriente antigo, o livro tinha a forma de tábulas de madeira ou de bambu atravessadas por uma fivela que as mantinha unidas e nelas se escrevia verticalmente com o auxílio de estiletes banhados em uma espécie de esmalte. Do século $\mathrm{V}$ a.C. até o século XV de nossa era, o livro esteve associado ao trabalho do escriba ou copista, que o forjava através de uma laboriosa escrita e de invulgares iluminuras em rolos de pergaminho, papiro, velino ou papel de linho. Nem sempre o livro tinha um autor. Quando tinha, o autor (isto $\dot{e}, o$ poeta, o filósofo, o cientista) não era propriamente aquele que escrevia: ele apenas ditava seus pensamentos aos escribas, que depois os editavam em livros, naturalmente de acordo com o maior ou menor refinamento literário de cada um.

A cultura do manuscrito está longe de ser uma cultura menor ou mais limitada do que a tipográfica. Recordemo-nos de que a cópia de livros era considerada um trabalho intelectual na Idade Média: copiar um texto era uma maneira de estudá-lo (às vezes também de alterá-lo, quando se discordava dele). Ademais, não podemos nos esquecer de que, até o século XV toda literatura existia, antes de mais nada, para ser recitada em público e o manuscrito era apenas um instrumento acessório dessa vasta e influente cultura oral, que nos deu pensadores como Pitágoras, Ścrates e Demócrito e poetas como Homero e os trovadores medievais.

Eis porque a idéia do livro não pode estar obrigatoriamente associada a um registro da palavra escrita. Platão, no Fedro, define o livro como logos gegrammenos (palavras escritas), mas a própria civilização em que ele se insere o desmente. Nas sociedades orais, os anciáos sáo lipros pipos, que guardam a memória da comunidade. Chaytor (1945:116) observa que se fossem perdidas todas as cópias impressas do Rigpeda, o livro sagrado dos indianos poderia ser imediata e facilmente reconstituído, porque qualquer cidadáo indiano sabe o texto de cor (o que é surpreendente se considerarmos que o livro é maior que a Iliada e a juntas). Nesse sentido, é bastante ilustrativa a fábula imaginada por Ray Bradbury em Fabrenbeit 451 e levada ao cinema por François Truffaut: para resistir a um regime totalitário que colocou o livro na ilegalidade e que condenou à fogueira todos os volumes existentes, cada cidadáo decide decorar o texto integral de um livro, de modo a preservar o seu conteúdo mesmo depois de queimados todos os exemplares impressos, dando início assim à geraçăo dos homens-livros. 
Homens-livros não são apenas privilégios de sociedades totalitárias ou de comunidades arcaicas pré-tipográficas. Mesmo no século XX, alguns de nossos mais importantes pensadores foram essencialmente pensadores orais. Vide os exemplos de Ferdinand de Saussure e Jacques Lacan, intelectuais decisivos para os rumos tomados pelo pensamento contemporâneo e que nos deixaram, paradoxalmente, pouquíssimos escritos de próprio punho. $\mathrm{Na}$ verdade, a obra de tais pensadores consiste principalmente em compilaçóes realizadas por seus alunos, com base em anotações de aulas. Outros intelectuais de nosso tempo igualmente decisivos - tais como Marx, Husserl, Peirce, Wittgenstein, Valéry, Benjamin, Eisenstein e tantos outros - , malgrado não possam evidentemente ser considerados pensadores orais, nos legaram, todavia, poucas obras publicadas. A parcela mais significativa de seus escritos chegou até nós na forma de toneladas de arquivos de anotações, sobre os quais se debruçam hoje os especialistas em busca de novos ensinamentos.

Certamente, homens como esses eram férteis demais para publicar livros; as idéias jorravam de suas cabeças numa velocidade tal que era humanamente impossivel dar-lhes acabamento final ou lustrá-las com o verniz da retórica erudita, sobretudo levando-se em consideraçáo o curto período de suas vidas. Eram artífices do pensamento e não fabricantes de parágrafos. Mas talvez a dificuldade de produzir livros tenha outra razão, não percebida pelos contemporâneos: é possível que, em última instância, o pensamento de tais homens fosse complexo demais para ser reduzido à camisa-de-força do texto impresso. É possível que o pensamento desses mestres resistisse ao controle de qualidade da escrita seqüencial, com sua lógica de inferências demasiado simplista, e se adequasse melhor a uma forma de registro não-linear, de que o arquivo de anotafōes era a única opção disponível em suas épocas. "O fichário representa a conquista de uma escrita tridimensional e, ao mesmo tempo, um retorno à tridimensionalidade da escrita tal como ela era praticada nos seus primórdios, através da runa e da grafia nodular" (Benjamin, 1978:78). Os especialistas dão a essas anotações o nome de manuscritos, como se a principal característica delas fosse o fato de não terem sido publicadas, como se o destino de todo pensamento fosse terminar impresso na forma do códice cristão. Mas não estará a obra dos pensadores mais decisivos de nosso tempo demandando um outro dispositivo de estruturaçáo, mais adequado à complexidade de suas descobertas?

"A idéia de que o conhecimento é essencialmente um saber de livros", afirma Marshall McLuhan (1972:113), "parece ser muito uma noção da época moderna, provavelmente derivada da distinção medieval entre clérigos e leigos, que veio dar nova ênfase ao caráter literário e um tanto extravagante do humanismo do século XVI". McLuhan é bastante 
conhecido pelo fato de ter sido um dos primeiros intelectuais a denunciar o caráter uniformizador e seriado do paradigma introduzido no ocidente pela imprensa de Gutenberg. Nossas instituiçóes intelectuais, entretanto, ainda parecem se deixar embalar pelas idéias esdrúxulas de que o conhecimento encontra-se associado exclusivamente ao modelo conceitual do texto impresso ou de que só se pode pensar com palavras, com palavras escritas preferencialmente. Persiste ainda largamente nos meios acadêmicos, sobretudo nas áreas das humanidades, uma tendência generalizada de confundir competência intelectual com talento para a escrita.

Algumas aulas de Jacques Lacan foram proferidas em programas de rádio e de televisão. A transcriçáo dos textos das aulas foram depois publicadas em livro (Lacan, 1974), mas poderíamos honestamente dizer que o texto impresso é mais legítimo do que os programas de rádio ou de televisão? Quantos livros impressos poderiam rivalizar em originalidade, extensão de pesquisas, profundidade de análise e autoridade científica com séries televisuais tais como Ways of Seeing, Inside the CIA: on Company Business, Planet Earth, The Powper of Myth, Vietnam: a Telenision History, The Living Planet, Sur et Sous la Communication, El Arte del Video ou a brasileira América? Falando sobre a dificuldade dos nossos contemporâneos em entender como a Europa pôde produzir rica tradição literária num período em que o livro impresso ainda não existia, Martin (1992:33) explica que, penetrados como estamos por uma cultura escrita, nossa imaginação náo consegue ser suficientemente prodigiosa para compreender o mecanismo das culturas orais. "Parece, contudo", completa ele, "que, em nossa época, os novos meios de difusão não-escrita do pensamento, como são o cinema e sobretudo o rádio, deveriam ajudar-nos a conceber melhor o que pode ser, para milhóes de indivíduos, uma transmissáo de obras e de idéias que não mais use o circuito normal do texto escrito". Levando em consideração o próprio conceito de livro já discutido acima (instrumento para dar consistência ao pensamento disperso e para ampliar o seu poder de influência dentro de uma sociedade), náo poderíamos pois dizer que os filmes, os vídeos, os discos e muitos programas de rádio e televisão são os lipros de nosso tempo?

\section{O livro como dispositivo}

Mas se considerarmos que as mídias dão continuidade, em nosso tempo, ao projeto histórico do livro, é preciso também considerar que, nesse mesmo movimento, elas o transformam, redirecionando-o em função das novas necessidades do homem contemporâneo. $O$ livro passa a ser pensado agora como dispositipo, como maquinaria, cuja função é náo apenas dar suporte ao pensamento criativo, mas também colocá-lo 
em operaçáo. Se antes considerávamos o livro como um recurso para colocar a memória do homem fora do próprio homem (dando-lhe assim maior poder de difusão e de permanência), memória todavia estática e resistente às mutaçóes do próprio homem, podemos agora visualizá-lo como uma máquina no interior da qual o pensamento já está a laborar.

Foi o escritor espanhol José Ortega y Gasset quem propôs, em 1939, a idéia um tanto exótica do livro-máquina. "O livro-máquina tem a finalidade de manter fora do homem, sem prejúzo de sua energia mental e, ao mesmo tempo, à sua permanente disposição, as informaçōes necessárias sobre as diversas ordens do pragmatismo humano. Algumas obras científicas alemãs e inglesas já são hoje verdadeiros aparatos que funcionam quase que automaticamente (sobretudo graças à refinada técnica de seus índices" (Ortega y Gasset, 1967:151). O primeiro grande exemplo de livro-máquina é o projeto da Enciclopédia de Diderot, iniciado no século XVIII: uma obra em 35 volumes (17 de texto, 11 de pranchas, quatro de suplementos, dois de índice e um de suplemento de pranchas), fruto do trabalho de $\mathbf{1 5 0}$ especialistas, quatro livreiros e 1.000 operários, que deveria dar conta do essencial acumulado em termos de conhecimentos até a época de sua publicação. A grande novidade introduzida pela Enciclopédia foi o conceito de estruturaçáo do(s) texto(s): tanto a ordem alfabética das entradas, quanto os índices de assuntos e as palavras-chave que remetem a outras partes da obra dão um sentido inteiramente novo ao livro: náo se trata mais de uma obra para ser lida por inteiro, da primeira à última página, mas de um dispositivo de organização do pensamento, no qual se pode penetrar de forma não-linear, a partir de qualquer ponto e dele saltar para qualquer outro, de modo a descobrir apenas aquilo que no momento estamos procurando. Em outras palavras, trata-se de um livro-farol, destinado a iluminar os caminhos e auxiliar o trabalho de navegaçáo, livro ao qual devemos retornar a todo momento, como a uma bússola, como ao mapa de um terreno, sempre que decidimos traçar nosso próprio caminho.

O projeto da Enciclopédia influenciou profundamente a própria história do livro. Não apenas deu o modelo dos chamados livros de referência (dicionários, manuais e as próprias enciclopédias), como também contribuiu para um certo aperfeiçoamento da própria idéia do livro. Muitos livros hoje produzidos, sobretudo nas diversas áreas das ciências ditas exatas, utilizam procedimentos inspirados na Enciclopédia, como é o caso dos boxes de informaçóes paralelas, ilustraçōes detalhadamente comentadas, glossários minuciosos, bem como índices analíticos e onomásticos sofisticadíssimos, que possibilitam entradas nãolineares no texto. Mas a idéia do livro-máquina teria que desembocar na 
máquina propriamente dita, no computador, onde daria nascimento a obras eletrônicas audiovisuais e não-lineares, com acesso aleatório a qualquer de suas partes, dotadas de mecanismos de busca extremamente avançados (como os baseados na álgebra booleana), construídas sobre estruturas tridimensionais simultâneas (que permitem dispor vários textos na tela ao mesmo tempo, para leitura comparativa, ou abrir na tela janelas através das quais se pode visualizar outros trechos relacionados ao texto atualmente exibido), obras, ainda, que se pode distribuir $e$ acessar por via telefônica ou por ondas eletromagnéticas, através de bibliotecas virtuais informatizadas.

As grandes teorias dos últimos quinhentos anos, bem como as explicaçōes sistemáticas dos grandes pensadores e mesmo determinadas concepçōes filosóficas de verdade (fundadas sobre a objetividade e a universalidade) estiveram baseadas grandemente em certas estabilidade e unicidade que, de alguma forma, o livro impresso garantia. Hoje, com o pensamento em permanente metamorfose, tudo isso nos parece excessivamente fixo e bem pouco operativo. A partir das escrituras hipertextuais, costuma-se dizer que o escritor, o crítico, o cientista já não mais escrepem textos; eles processam idtias. Conforme Pierre Lévy (1993), o espírito humano conheceu, ao longo da história, três tempos distintos: o da oralidade (baseado na memória, na narrativa e no rito), o da escrita (baseado na interpretaçăo, na teoria e na legislaçăo) e, finalmente, o da informática (baseado na modelização operacional e na simulação como forma de conhecimento). "As teorias, com suas normas de verdade e com a atividade crítica que as acompanha, cedem terreno aos modelos, com suas normas de eficiência e o julgamento de pertinência que preside sua avaliação. O modelo não se encontra mais inscrito no papel, este suporte inerte, mas roda em um computador. E desta forma que os modelos são continuamente corrigidos e aperfeiçoados ao longo das simulaçóes. Um modelo raramente é definitivon" (Lévy, 1993:120).

Na verdade, a história do livro sempre esteve associada a dispositivos de escrita ou de leitura, de modo que a assimilaçáo da idéia do livro à tecnologia do período não é privilégio de nosso tempo. Recordemonos de que, na Idade Média, a leitura do manuscrito exigia a invocaçáo de todo um aparato técnico: não apenas era preciso recorrer a um sistema de cavaletes e alavancas, porque o livro era um volume demasiado amplo e pesado para ser manuseado (às vezes até com capas de ferro fundido e grandes fechaduras), como também o conceito de leitura era completamente distinto do que predomina hoje: ler era necessariamente fazê-lo em voz alta, o que exigia o concurso de uma cela ou de um cubículo fechado, de preferência à prova de som. Esta é a razáo por que 
McLuhan (1972:135) chamava o local de leitura dos monges medievais de cabines de som, algo muito semelhante às atuais cabines telefônicas.

A história do livro relaciona-se também, embora indiretamente, com as técnicas da mnemônica desenvolvidas pelos gregos antigos e consideradas por Cícero uma das cinco partes da retórica clássica. Tratava-se, então, de criar procedimentos de memorizaçáo através de recursos artificiais auxiliares, tais como a associaçáo daquilo que deve ser memorizado com certos lugares ou imagens. Nos séculos que antecederam a invenção da imprensa, o treinamento da memória era considerado uma atividade de vital importância e dela dependia, em grande parte, a sobrevivência da ciência e da cultura. $O$ excelente tratado de Frances Yates (1966) sobre a arte da memória traça o panorama histórico dos vários procedimentos utilizados por diferentes povos para incrementar o poder de fixação da memória, inclusive com a construção de cenários arquitetônicos ou teatrais destinados à atuaçáo dos elementos mnemônicos. Ao longo desse panorama, destacam-se, já no Renascimento, dispositivos tâo exóticos quanto engenhosos, como o teatro da memória de Giulio Camillo, os sistemas de memorização de Giordano Bruno e outro sistema teatral creditado a Robert Fludd, a maioria deles ligados à tradiçăo cabalística. Todos esses engenhos sáo mais ou menos contemporâneos da invenção da imprensa e, embora direcionados em perspectiva diversa, visavam dar respostas a um mesmo tipo de problema, qual seja a necessidade de dispositivos mais eficazes de fixação da memória humana, inclusive em suportes externos, capazes de resistir à efemeridade do corpo do homem. Apenas a imprensa vingou historicamente, mas, como já observou Greg Ulmer (1991:4), em nosso tempo, o desenho de aplicativos hipermídias em geral tem muito em comum com o projeto dos teatros mnemônicos do Renascimento hermético-cabalístico.

Resta uma última questão a examinar. Por que o livro impresso é substituído por dispositivos informatizados de leitura, por livrosmáquinas ou livros eletrônicos interativos que trafegam em cabos telefônicos ou ondas hertzianas? Pode-se explicar esse fenômeno sob um enfoque econômico, como uma estratégia das multinacionais da eletrônica e da informática para monopolizar todos os mercados. Mas isso seria uma extrema simplificação. A verdade é que o universo do texto impresso chegou ao seu limite de saturaçáo e hoje degenera em entropia, em virtude da dificuldade cada vez maior de gerar significados consistentes. $O$ universo do livro se agigantou de tal forma que hoje padece de uma doença crônica, a elefantíase. No século XIV, às vésperas da revoluçăo da imprensa, a biblioteca da Sorbonne, tida como a maior da Europa, contava com um acervo de 1.228 livros. Hoje, as maiores 
bibliotecas do mundo abrigam cada uma por volta de dez milhōes de volumes. Só a Biblioteca do Congresso de Washington cataloga a bagatela de dez títulos novos por minuto! Estima-se que, atualmente, em qualquer parte do mundo, uma biblioteca razoavelmente atualizada duplica de tamanho a cada 14 anos (Wurman, 1991:219-235). Estamos nos aproximando perigosamente da biblioteca-monstro imaginada por Jorge Luis Borges. O corolário inevitável desses números é que se torna cada vez mais impossível a um ser humano normal manter-se em dia com o que se publica no planeta, mesmo limitando-se apenas às três ou quatro línguas mais utilizadas para a comunicação internacional e restringindo todas as suas leituras exclusivamente a uma área específica de especialização.

Em nosso tempo, precisamos de outras espécies de livros, de literatura, de revistas especializadas e de obras de referência. É preciso que os novos livros funcionem como máquinas, à maneira da Encicloptdia de Diderot, e sinalizem os seus caminhos, para que o leitor possa entrar facilmente em suas avenidas e encontrar rapidamente o que procura. É preciso que as obras estejam abertas à navegaçáo do leitor, para que ele escolha livremente o seu percurso e faça suas próprias descobertas. É preciso que os dispositivos de pesquisa sejam ágeis e inteligentes, permitindo chegar-se ao conhecimento desejado com um mínimo de atropelos e sem constrangimentos de ordem geográfica, econômica ou institucional. É preciso ainda que os atuais $\mathbf{e}$ infindáveis exercícios de retórica sejam substituídos por textos condensados, dotados da precisão de um diagrama e da velocidade de um haicai. Acima de tudo, os novos livros deverão ser escritos em camadas ou níveis diferenciados de aprofundamento, aproveitando a estrutura tridimensional das escrituras hipertextuais, de modo que se possa fazer uma leitura apenas informativa, quando se quer somente saber do que se trata, mas também se possa mergulhar fundo na argumentaçáo, se $o$ interesse do leitor vai mais longe.

Para se chegar lá, mudanças estruturais profundas deverão ocorrer no que diz respeito aos mercados editoriais, aos hábitos de leitura, à rotina acadêmica nas universidades e ao processamento de informaçôes naquilo que hoje chamamos de bibliotecas. Bancos de dados inteligentes deverão substituir os inexpressivos fichários atuais; novos softwares ajudarăo na tarefa de localizar, selecionar e compreender a informação; empresas de processamento ofereceráo serviços especializados de resumos, sumários e pré-leitura; novos canais de distribuiçáo, muitos deles on line, deveráo condenar ao esquecimento as atuais livrarias. Tudo isso acontecerá mais cedo do que se imagina. Em alguns lugares do Primeiro 
Mundo, o perfil das bibliotecas já está mudando radicalmente. Em muitas delas, os livros estão sendo digitados e armazenados em CD-ROMs ou em gigantescas memórias on line, de modo a permitir o acesso remoto e a pesquisa a partir de qualquer palavra na língua-sede. Dentro de mais algum tempo, muitas bibliotecas não terão sequer um único livro impresso para expor em suas prateleiras, se é que ainda terão prateleiras.

O movimento nesse sentido é irreversível. Uma quantidade cada vez maior de lipros é editada em videocassetes, em disquetes ou em CD-ROMs e distribuídos em lojas de departamentos ou em birôs de artigos eletrônicos (uma vez que a maioria das livrarias se recusa a expôlos em suas estantes). Uma nova espécie de literatura emerge do limbo e promete surpresas jamais sequer sonhadas pelos poetas de outros tempos. Agrippa (1992), do novelista William Gibson e do artista gráfico Dennis Ashbaugh talvez seja a proposta mais provocativa nesse sentido: trata-se de um romance eftmero, que vai sendo embaralhado e destruído por uma espécie de vírus de computador no mesmo momento em que é lido, de modo que você só tem uma única chance de conhecê-lo, se for suficientemente rápido. The Madness of Roland (de Greg Roach), aplicativo multimídia tido pelos especialistas como o primeiro romance interativo da literatura, é uma história medieval construída através de várias camadas de comentários e diferentes focos narrativos, de modo a permitir forjar narrativas distintas umas das outras, conforme o ponto de vista e o nível de comentário adotado. No terreno da literatura infantil, living books distribuídos em discos CD-ROM, tais como Mixed-up Mother Goose (de Roberta Williams) e Just Grandma and Me (de Mercer Mayer), não apenas juntam em um só contexto música, imagens animadas, texto escrito e voz oralizada em várias línguas, como também possibilitam construir histórias mutantes, que se modificam cada vez que se volta a elas. E se quisermos um exemplo brasileiro, basta lembrar o impressionante retorno da oralidade no $C D$ registrado por Haroldo de Campos (1992), com a leitura de 16 fragmentos de suas Galáxias.

Se o livro vai morrer ou não, essa é uma discussão restrita apenas aos círculos de filólogos, pois, no fundo, tudo é uma questão de definir o que estamos chamando de livro. O homem continuará, de qualquer maneira, a inventar dispositivos para dar permanência, consistência e alcance ao seu pensamento $e$ às invençóes de sua imaginaçáo. $E$ tudo fará também para que esses dispositivos sejam adequados ao seu tempo. A sabedoria, como dizia Brecht, continuará sempre passando de boca em boca, mas nada impede que estendamos um microfone às bocas que falam, para thes dar maior alcance. 


\section{Referências bibliográficas}

BENJAMIN, Walter. Reflections: essays, aphorions, autobiograpbical writings. New York, Helen \& Kurt Wolff, 1978.

CAMPOS, Haroldo de. Isto nuto d vom livro de viagem (CD). Rio de Janeiro, Ed. 34, 1992.

CHAYTOR, H.J. From script to print. Cambridge, Heffer \& Sorts, 1945.

EVARISTO ARNS, Dom Paulo. A ttenica do liwro segundo Sáo Jeronimo. Rio de Janeiro, Imago, 1993.

GIBSON, William \& ASHBAUGH, Dennis. Agrippa (a book of the dead) (disquete). New York, Kevin Begos, 1992.

GREAT Literature Personul Library Series (CD-ROM). Parsippany, Bureau Development, 1992.

LACAN, Jacques. Telerision. Paris, Ed. du Seuil, 1974.

LEVY, Pierre. As tecnologias da intelighncia. Rio de Janeiro, Ed. 34, 1993.

McLUHAN, Marsball. A galdaxia de Gutenberg. São Paulo, Cia. Ed. Nacional, 1972.

MARTIN, Henry-Jean \& FEBVRE, Lucien. O aparecimento do limro. São Paulo, Hucitec/Ed.Unesp, 1992.

ORTEGA Y GASSET, José. Misión del bibliotecario y otros ensayos afines. Madrid, Revista de Occidente, 1967.

ULMER, Greg. Grammatology hypermedia. Postmodern Culture (periódico on-line ), v. l, n. 2 , jan. 1991.

WURMAN, Richard Saul. Ansiedade de informagăo. Săo Paulo, Cultura, 1991.

YATES, Frances. The art of momory. Chicago, University of Chicago Press, 1966.

\section{Resumo}

O texto levanta hipóteses a respeito das rafzes clássicas dos atuais livros eletrônicos. Ao traçar paralelos entre o hipertexto ou a hipermídia e a retórica praticada na Grécia antiga ou na cultura oral da Idade Média, ele oferece um aporte intelectual para entender as profundas mudanças que estāo se processando no universo da ediroraçăo. Hoje, livros eletrônicos simulam na tela dos computadores o ambiente familiar do livro convencional, mas ao mesmo tempo introduzem inovaçōes, tais como a possibilidade de estabelecer ligaçōes dinâmicas e de exibir som e vídeo.

\section{Abstract}

The text presents hypothesis about the classical roots of today's electronic books. Tracing 
hypertext and bypermedia back to the rhetoric practiced in ancient Greece and mediaeval oral culture, it offers an intellectual context and a background to understand the rapid changes in the universe of publishing. Today, electronic books replicare the familiar environment of a book for computer screens, though adding new features like dynamic links and sound or video playback.

Arlindo Machado é professor do Departamento de Ginema, Rádio e TV da Escola de Comunicaçóes e Artes da USP e do Programa de Pós-Graduaçāo em Comunicaçāo e Semiótica da PUC-SP. É autor de $A$ arte do vídeo (1987), Máquina e imaginário (1993) e do livro eletrônico (editado em CD-ROM) Ensaios sobre a contemporaneidade (1994).

Palestra feita pelo autor em 12 de maio de 1994 no IEA. 